\title{
CONCEPT OF AN INTEGRATED MOBILE APPLICATION AIDING ELECTROMOBILITY
}

\author{
Csaba CSISZÁR, Gábor PAUER* \\ Dept of Transport Technology and Economics, Faculty of Transportation Engineering and Vehicle Engineering, \\ Budapest University of Technology and Economics, Hungary
}

Received 1 March 2017; revised 16 September 2017, 19 October 2017; accepted 25 November 2017

\begin{abstract}
Increasing acceptance of electromobility is an important step towards sustainable transportation. However, besides its obvious environmental and economic benefits, the technology of Electric Vehicles (EVs) still has some significant operational drawbacks (e.g. relatively short driving range, long recharging time). Advanced mobile applications supporting travellers' decisions, improving predictability and reliability could play a key role in the promotion of a more widespread use of the technology. Mobile applications can serve as a "platform" between the human component and the integrated system. The aim of our research was to reveal the correspondences between functions, data groups and system components, to create the concept of a complex, integrated information application and to elaborate its innovative functions. As a result of our systematic analysis of the most important, currently available applications, it has been found that important, customizable functions (e.g. charger-point reservation, energy-efficient routing etc.) are not yet available, thus our innovation focused on these information management features. Based on our concept, integrated information applications can be developed, providing real-time personalized service for the users and including all functions related to electromobility.
\end{abstract}

Keywords: electromobility, mobile application, information management, integration, electric vehicle, functional model.

\section{Notations}

Variables and functions:

d - dynamic data;

$D_{i} \quad$ - data group $i$;

$F_{i} \quad$ - function $i$;

$P_{c} \quad$ - charging speed of selected spot $[\mathrm{kW}]$;

$Q_{b} \quad$ - battery capacity [kWh];

$s \quad$ - static data;

$S O C_{b}$ - state of charge [\%];

$t \quad$ - time of charge [h];

$\eta \quad$ - efficiency of charge [\%].

Abbreviations:

BEV - battery-only electric vehicle;

DSO - distribution system operator;

EV - electric vehicle;

ID - identity document;

IT - information technology;

$\mathrm{I} 2 \mathrm{~V}$ - infrastructure-to-vehicle;

RFID - radio-frequency identification;

SMS - short message service;

TCO - total cost of ownership;

V2G - vehicle-to-grid;

$\mathrm{V} 2 \mathrm{~V}$ - vehicle-to-vehicle.

\section{Introduction}

The market for EVs or BEVs is still a niche market. This is mainly due to limited direct user experience, lack of public information and (perceived) cost of vehicles and infrastructure. Therefore, the operation of EVs evokes specific challenges toward drivers. Nevertheless, the use of EVs in urban areas has a great potential in improving the quality of mobility on the one hand and decreasing traffic-related problems on the other hand, such as traffic congestions and exhaust emission overload. To achieve EV impact in terms of sustainable cities, a transformation is necessary from the current niche market into a mainstream market, where EVs are a "natural" and viable transportation mode, both by individual consumers, by fleet owners and logistic service providers. Accordingly, there is an urgent need to explore essential conditions for deployment.

Advanced personalized information services can significantly improve user experience and moderate drawbacks of EVs. The mobile applications, as convenient ubiquitous information sources are the most appropriate tools to support several functions related to the operation (decision-making, navigation, guiding, etc.). In this innovative topic, we performed a comprehensive literature

${ }^{*}$ Corresponding author. E-mail: pgabor90@gmail.com 
review focusing on value of information, mobile applications and operational issues of electromobility. Importance of value-added information in transportation has been recognized in several researches (Wydro 2011), pointing out that value of information can be measured as effect of its influence on decisions (Wydro 2010). The need for personalized information is also essential for each passenger, regardless of knowledge of the network and/or mobility services (Tavares et al. 2015).

The quick development and spread of various information applications can be observed. In developing countries, more than $60 \%$ of people have a smartphone, from which $75 \%$ uses their device for collecting transport related information and navigation (ThinkMobile 2011). Information is mostly acquired through applications, which have more significant impact than traditional information systems (Khoo, Ong 2011).

Spread of information services via portable devices forces mobile telecommunication operators to make heavy investments to upgrade and expand their networks (Feijóo et al. 2016). Even so, many mobile applications do not perform well due to the shortage of resources for computation, data storage or network bandwidth. However, applications can be re-designed with client-server models to benefit from cloud services (Hung et al. 2012).

Information systems have a key role in novel transportation modes, like electromobility, which becomes an important part of smart city concepts (Pribyl, Svitek 2015). Integration of the road transport and power systems into smart grid requires implementing of novel information services aiding coordination of individual electricity demands and network capacities through smart charging (Daina et al. 2017). The research of Hübner et al. (2012) discussed advanced information systems and services via mobile applications as a priority for future Intelligent Transport Systems (ITS) developments to tackle drawbacks of EVs. However, the novel information management functions are barely devised and the theory of operations is scantly published in scholar papers (Merlino et al. 2016; Sankaran et al. 2016; Walravens 2015). As our department achieved several scientific results in field of conceptual modelling of mobility related integrated mobile applications (Cserháti, Csiszár 2016; Földes, Csiszár 2015; Karádi et al. 2015) we extended our focus towards electromobility considering its specialties.

In order to develop complex information systems theoretical correspondences regarding the structure and the operation are to be revealed. Axioms used in the theory of information systems have been investigated, and notion of simplified continuous information system has been introduced in research by Huang et al. (2016). Samper-Zapater et al. (2015) have described a multi-agent platform for traveller information systems, while in the research of Gonzalez et al. (2016) an in-depth description of information systems outsourcing has been provided.

Consequently, seeing/identifying the specific emerging functions required during operation of EVs, the lack of personalized, value-added information, the "fragmented" available solutions as well as the challenges in integration, our recent research focused on this topic and we tried to fill this "niche" by our results. To develop novel functions and combine these functions as well as data related to electromobility in an application; furthermore, to integrate this mobile application into the entire system managing operation of EVs, the theoretical background should be elaborated. Accordingly, during elaboration of the integrated mobile application on conceptual level, the research aims were to itemize the challenges and deficiencies, to determine the conditions of integration, to identify the system components, the functions and the data groups, to reveal the correspondences between components, functions and data, and to model the correspondences.

We applied system- and process-oriented approach. The information management functions were built on the physical processes. We focused mainly on users' functions and expectations; however, the functions of operators, electricity providers, etc., have also been considered.

The entire concept including all required functions and their interrelations is presented here highlighting the most important one in detail. Section 1 summarizes the state-of-the-art; namely, the characteristics and exemplary features of currently available applications. Section 2 describes the concept of the integrated application, presenting the operational model and system architecture. In Section 3, function "reservation of charging spot" has been elaborated. Finally, concluding remarks have been provided.

\section{State-of-the-art}

Current information applications have been analysed according to several aspects. The selected applications are widely used, popular or having unique features and functions:

- Holtoltsek.hu: conventional web application providing comprehensive information about Hungarian charging stations;

- PlugSurfing: web and mobile application with European charging stations, promoting use of compatible charging points;

- Charge\&Drive: web application with charging stations in the Nordics, operated by energy provider company called Fortum;

- ChargePoint: web and mobile application of company called ChargePoint; supporting the search and use of charging stations in the US, with some functions to promote the use of EV;

- PlugShare: community-based, web and mobile application covering all continents, having the largest database about charging stations;

- GreenCharge: mobile application supporting use of the EVs (Nissan Leaf, Prius Plug-in and Ford Focus $\mathrm{EV}$ ) and providing various statistics about cost savings, economic effects and driving habits. 
The evaluated main functions $F_{i}$ of the applications were the following:

- $F_{1}$ : vehicle selection, purchase decision;

$-F_{2}$ : charge planning;

$-F_{3}$ : driving assistance;

$-F_{4}$ : charging;

$-F_{5}$ : payment.

The functions have been further disaggregated as well as the main operational features have been identified and investigated (Tables 1 and 2). The sub-functions and operational features are discussed in more detail in Section 2 with the explanation of the new concept. During situation analysis, we had already plans regarding the novel functions. Therefore, we were looking for these functions as well as integrated functions and opportunities for integration with particular attention.

General findings of the analysis:

- number of applications and information services are expanding;

- support of using EVs (through communication with the vehicle) is not typical yet;

- functions are usually rather limited (mainly aiding the charging process, seldom supporting the use of vehicles);

- beside information provision, service functions are gaining importance (start/stop charging process, automatic payment, etc.);

- provision of dynamic data (reservation status, calculated fee, etc.) is prevalent;

- decision support regarding vehicle purchase, dynamic information about services around charging stations, estimation of charging times, preliminary reservation of charging spots, energy-efficient route planning, and support of Smart Grid solutions are currently not available;

- accessibility on smart devices (smartphones, in-vehicle displays) is increasing;

- differences of chargers (e.g. in technical, operational, organizational sense) cause significant difficulties: the charging functions (with dynamic data) are mostly limited to chargers of only a few service providers.

Exemplary features:

- some applications provide information about more than 10000 charging stations;

- with the app called PlugShare, users can also share their private (residential) chargers;

- the PlugShare is able to show terrain view, which is useful because terrain data have impact on energy consumption;

- the Charge\&Drive app and the Holtoltsek.hu webpage have own route planner; PlugShare and ChargePoint are integrated with available software (Google Maps, Apple Maps, Waze);

- ChargePoint and GreenCharge receive data from the vehicle through time-controlled automatic synchronizations; therefore, they can provide supplementary information to the drivers.
During situation analysis, we have ascertained that some functions are not available yet, although they are useful and have various benefits (e.g. improving predictability). Therefore, accessible functions are to be complemented/integrated with devised innovative and improved functions. There are already some exemplary current applications, but these are rather limited in regard of both functionality and use of real-time data.

\section{Concept of integrated information application}

In order to improve and complement the existing applications a novel concept has been elaborated. The presented concept consists of the operational model and system architecture.

\subsection{Operational model}

Operational structure of the application is rather complex; which can be described by the connections and the flowing data between the functions. The operational model contains exemplary, improved and devised new functions (Table 1) and prosperous features (Table 2). The required data groups have also been identified (Table 3 ) and assigned to the functions.

The function of route planning includes the option to plan the most energy-efficient route. Two-way communication between the application and the vehicle is needed for the automatic customization/parameterization of the application, and for the evaluation of driving profiles. The innovative functions use data provided by the vehicle and taking the user's preferences into account (self-learning). For instance, calculation of TCO or return uses consumption, mileage and historical charging data.

Compatible charging spots are automatically displayed by the application (e.g. when searching for charging stations or starting a reservation process). Some real-time notifications are based on the actual status of vehicle. The "feedback" function facilitates improvement of charging services, vehicles, information applications, etc.

Model summarizing the time and logical dependency, as well as the embedding of functions of the application is shown in Figure 1. Notations (indices and colours) are the same as before. Horizontal place of the boxes indicates time sequence (from left to the right). Logical dependency between functions means that use of previous function is mandatory for operation of the next, logically dependent function. Those functions are to be integrated:

- which use common input data groups (e.g. $F_{3,2}$ and $F_{3,3}$ ) and/or,

- where the procedures match partially or entirely (e.g. $F_{4,4}$ and $F_{5,1}$ ), as well as,

- which can be performed at the same time and place during travel (e.g. $F_{3,2}$ and $F_{3,3}$ ).

Route planning is required for navigation. Identification is needed before starting the charging process and charge should be stopped before calculating the fee. 
Table 1. Functions of the integrated application

\begin{tabular}{|c|c|c|c|c|}
\hline \multicolumn{2}{|c|}{ Notation } & Sub-functions & Details & Data groups \\
\hline \multirow{2}{*}{$F_{1}$} & $F_{1,1}$ & Information about TCO & $\begin{array}{l}\text { integration of a cost model with customized/automatically } \\
\text { calibrated model parameters (based on driving habits) }\end{array}$ & $D_{1}^{s}, D_{1}^{d}, D_{2}^{s}, D_{7}$ \\
\hline & $F_{1,2}$ & Calculation of return & $\begin{array}{l}\text { based on personal/automatically calibrated data, comparison } \\
\text { with conventional vehicles }\end{array}$ & $D_{1}^{s}, D_{1}^{d}, D_{2}^{s}, D_{7}$ \\
\hline \multirow{4}{*}{$F_{2}$} & $F_{2,1}$ & $\begin{array}{l}\text { Information provision } \\
\text { about charging spots }\end{array}$ & $\begin{array}{l}\text { customized information based on users' preferences } \\
\text { and vehicle parameters }\end{array}$ & $\begin{array}{l}D_{2}^{s}, D_{3}^{s}, D_{3}^{d}, D_{4}, D_{5}^{s}, \\
D_{5}^{d}, D_{7}\end{array}$ \\
\hline & $F_{2,2}$ & $\begin{array}{l}\text { Information provision } \\
\text { about services around } \\
\text { charging stations }\end{array}$ & $\begin{array}{l}\text { dynamic information, completed with optional services (e.g. } \\
\text { booking a table in nearby restaurant) }\end{array}$ & $D_{1}^{d}, D_{3}^{s}, D_{5}^{s}, D_{5}^{d}, D_{7}$ \\
\hline & $F_{2,3}$ & $\begin{array}{l}\text { Estimation of charging } \\
\text { times }\end{array}$ & preliminary calculation based on data of vehicle and charger & $D_{2}^{s}, D_{2}^{d}, D_{3}^{s}$ \\
\hline & $F_{2,4}$ & $\begin{array}{l}\text { Reservation of charging } \\
\text { spot }\end{array}$ & $\begin{array}{l}\text { with consideration to user's expectations, state of charge } \\
\text { of vehicle, destination, etc. }\end{array}$ & $D_{1}^{s}, D_{3}^{s}, D_{3}^{d}, D_{4}, D_{5}$ \\
\hline \multirow{4}{*}{$F_{3}$} & $F_{3,1}$ & Route planning & with option to plan the lowest energy consumption & $D_{2}^{s}, D_{2}^{d}, D_{3}^{s}, D_{5}^{s}, D_{5}^{d}$ \\
\hline & $F_{3,2}$ & Navigation & location-based information services & $D_{2}^{d}, D_{3}^{s}, D_{5}^{s}, D_{5}^{d}$ \\
\hline & $F_{3,3}$ & Eco-driving & $\begin{array}{l}\text { recommendations based on predicted situation; using I2V/V2V } \\
\text { info-communication technologies; improvement of energy- } \\
\text { efficiency }\end{array}$ & $D_{2}^{d}, D_{4}, D_{5}^{d}, D_{7}$ \\
\hline & $F_{3,4}$ & $\begin{array}{l}\text { Real-time notifications } \\
\text { during driving }\end{array}$ & $\begin{array}{l}\text { based on data of vehicle, chargers, reservation processes, } \\
\text { providing information for displays of vehicles }\end{array}$ & $D_{2}^{d}, D_{3}^{d}, D_{5}^{d}, D_{7}$ \\
\hline \multirow{4}{*}{$F_{4}$} & $F_{4,1}$ & $\begin{array}{l}\text { Identification of user/ } \\
\text { vehicle }\end{array}$ & $\begin{array}{l}\text { identification by the application (wireless communication/SMS/ } \\
\text { RFID card) }\end{array}$ & $D_{1}^{s}$ \\
\hline & $F_{4,2}$ & Start/stop charging & feasible at every station through the application & $D_{1}^{s}, D_{4}$ \\
\hline & $F_{4,3}$ & $\begin{array}{l}\text { Real-time notifications } \\
\text { during charging }\end{array}$ & $\begin{array}{l}\text { about charging process and vehicle, personalized alerts based } \\
\text { on calculated charging time }\end{array}$ & $D_{2}^{s}, D_{2}^{d}, D_{3}^{d}, D_{6}, D_{7}$ \\
\hline & $F_{4,4}$ & $\begin{array}{l}\text { Smart Metering and Smart } \\
\text { Grid function }\end{array}$ & $\begin{array}{l}\text { "balancing" between power generation and consumption; based } \\
\text { on advanced V2G technologies, application of dynamic rates }\end{array}$ & $D_{4}, D_{6}, D_{7}$ \\
\hline \multirow{3}{*}{$F_{5}$} & $F_{5,1}$ & $\begin{array}{l}\text { Calculation of charging } \\
\text { fee (based on smart } \\
\text { metering) }\end{array}$ & $\begin{array}{l}\text { dynamic calculation of charging fee, calculation of savings } \\
\text { compared to conventional vehicles }\end{array}$ & $D_{3}^{d}, D_{4}, D_{6}$ \\
\hline & $F_{5,2}$ & Payment transaction & $\begin{array}{l}\text { automatic transfer of charging fee to the operator, support } \\
\text { of various payment methods }\end{array}$ & $D_{1}^{s}, D_{1}^{d}$ \\
\hline & $F_{5,3}$ & $\begin{array}{l}\text { Archiving charging data } \\
\text { and invoices }\end{array}$ & $\begin{array}{l}\text { archiving in exportable way, creation of statistics } \\
\text { for users and operators }\end{array}$ & $D_{1}, D_{3}^{d}, D_{4}, D_{6}$ \\
\hline
\end{tabular}

Notes: dark grey - exemplary existing functions; light grey - functions are to be improved; white - devised, entirely new functions.

Table 2. Features of the integrated application

\begin{tabular}{|l|l|}
\hline \multicolumn{1}{|c|}{ Operational features } & \multicolumn{1}{c|}{ Details } \\
\hline Availability & web/mobile apps (iOS, Android, Windows, etc.) \\
\hline Accessible stations/plugs according to ownership & public and private chargers shared by users \\
\hline Customization & automatically, partially based on data provided by vehicle \\
\hline Feedback options & rating, and text feedbacks \\
\hline Visual interface & map/satellite/terrain views \\
\hline Option to add information & users can edit existing/add new data (revision and approval required) \\
\hline
\end{tabular}


Table 3. Data groups used by the application

\begin{tabular}{|c|c|c|c|}
\hline \multicolumn{2}{|c|}{ Notation } & Data groups & Details \\
\hline \multirow{2}{*}{$D_{1}$} & $D_{1}^{s}$ & Static data of users & user ID, owned vehicles, personal data, payment preferences, etc. \\
\hline & $D_{1}^{d}$ & Dynamic data of users & driving profile, status, statistics, etc. \\
\hline \multirow{2}{*}{$D_{2}$} & $D_{2}^{s}$ & Static data of vehicles & vehicle ID, battery capacity, average consumption, charging speed, plug type, etc. \\
\hline & $D_{2}^{d}$ & Dynamic data of vehicles & position, range, state of charge, actual consumption etc. \\
\hline \multirow{2}{*}{$D_{3}$} & $D_{3}^{s}$ & Static data of chargers & $\begin{array}{l}\text { charging spot ID, maps, number and type of plugs, charging speed, conditions } \\
\text { of use and parking, available services, efficiency, etc. }\end{array}$ \\
\hline & $D_{3}^{d}$ & Dynamic data of chargers & occupancy, failures, etc. \\
\hline \multicolumn{2}{|c|}{$D_{4}$} & Electrical network data & price of energy, data needed for Smart Grid services, data of charger operators, etc. \\
\hline \multirow{2}{*}{$D_{5}$} & $D_{5}^{s}$ & Static data of environment & infrastructure parameters, location of chargers and services, etc. \\
\hline & $D_{5}^{d}$ & Dynamic data of environment & real-time traffic data, real-time data of services, etc. \\
\hline \multicolumn{2}{|c|}{$D_{6}$} & Data of charges & start time, reservation status, fee, etc. \\
\hline \multicolumn{2}{|c|}{$D_{7}$} & Feedbacks & about vehicles, chargers, service and information application \\
\hline
\end{tabular}

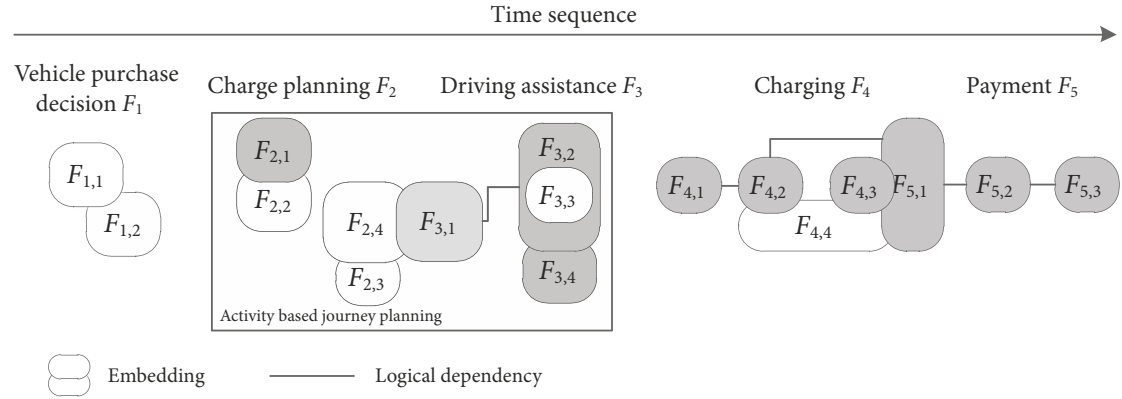

Figure 1. Model of the integrated application (correspondences and dependencies of functions)

Automatic payment and archiving of invoices may take place only after that. Information provision about charging stations and services may be performed at the same time; preliminary charging time estimations and route planning is partly embedded in reservation function. Supporting of eco-driving is completely, real-time driving alerts are partly embedded into the process of navigation.

Start/stop of charging process and notifications about it are supported by Smart Metering and Smart Grid functions. Fees are calculated when charging has been stopped (logical dependency). Energy stream between the power system and the vehicle can be controlled by both "sides" in order to find optimum solution. Accordingly, the physical connection between the charger and the vehicle does not imply the charging process by all means. Electricity system operators prefer energy selling during "underloaded" time periods, when capacities are higher than demands. For this purpose, either dynamic rates are applied or the energy stream blocked directly during "overloaded" time periods, when capacities are lower than demands. The charging may be controlled also by the user via the application. If the details of travels (flexibility features) are fed in advance, the energy is provided accordingly, with preference to the "underloaded" time periods. The following travel data are required for this function: departure time, covered distance (amount of consumed energy), probability of travel (e.g. work motivated travels have high probability). During elaboration of Smart Grid, function at public chargers the parking regulations are to be also considered.

The framed functions form the basis of activity based journey planning. Consecutive movements and activities are mutually interrelated; therefore, planning processes of them have to be integrated. Daily routine, activity plans and available time influence the selection of both charger and route and vice versa. Integration of the highlighted functions can be realized by embedding static and dynamic information provisions. As the activity based journey planning is an especially important novel function, we highlighted the dependency of sub-functions in Figure 2 to demonstrate the model's applicability for a certain function.

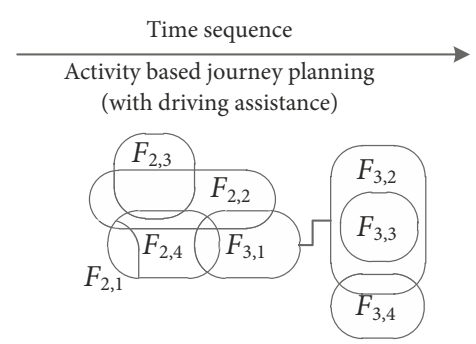

Figure 2. Functional model of activity based journey planning 


\subsection{System architecture}

The explained functions are served with a rather complex system, whose main components are: user interface (e.g. smartphone), application server and database server. The servers are connected to external systems and their databases. The application server is responsible for data exchange between the database server, the mobile application and the external systems. The most important external systems are on one hand the databases of charging network operators and on the other hand the EV traders (or manufacturers). The charging network operators cooperate with energy suppliers and DSOs. The central measurement and account system (clearing house) is also connected to the integrated system in order to facilitate the unified payment procedures.

This type of system architecture makes modularity with well-defined interfaces and separate development of the elements possible. Data transfer is to be realized through standard interfaces, which are implemented in the services. Data from some external systems are updated occasionally (e.g. static data of chargers), whereas several data need to be updated frequently according to longer/ shorter time-periods (e.g. dynamic data of vehicles and chargers). Implementation of integrated functions requires significant data flows between the system components (application, charger, vehicle and central measurement and account system).

Realization of innovative functions implies several legal (e.g. privacy of reservation data), organizational (e.g. type of cooperation between stakeholders, establishment of new organization for information management) and technological (e.g. expected characteristics of chargers) issues to be tackled. Reliable data required for operation are often difficult to access, because of several reasons (e.g. incentives for data owners are not elaborated).

\section{3. "Charging spot reservation" function}

The elaborated concept, as a theoretical framework, is a basis for deeper analysis and modelling of the certain functions. On the other hand, the detailed models of certain functions can be used for improvement of the integrated application. Namely, applying the top-down and bottom-up system engineering principles in an iteration process may result in more and more exact models and finally plans. In order to demonstrate the applicability, we present the function "Reservation of charging spot", which is one of the most innovative functions in the case of public chargers (e.g. in city centers, parking houses), where fast charging is required.

Introduction of this function is beneficial for each participant. Reservation appertains to one charging spot and the dedicated parking space (one station may have several spots). This new function has several advantages:

- journey can be planned in advance and being predictable;

- reliability of the vehicle is enhanced;
- capacity usage of charging spots is increased;

- load of power suppliers is also predictable.

The function is to be integrated with activity planning (in order to spend the charging time advantageously), route planning, navigation (with real time traffic data) and the automatic payment. For ad-hoc reservations, the charging stations should be complemented by touchscreen displays, which have the same functionality as the mobile application. Its implementation demands advanced IT (e.g. communication between the devices). When elaborating the function, the following constraints have been considered:

- the charging station has to communicate with the application and the vehicles (the charger identifies the plugged vehicle; the user of the car who pays for the charge can be identified according to the reservation data; the vehicle sends information about its' charging status for the application);

- preliminary registration is complemented by payment data and vehicle parameters (e.g. battery capacity);

- reservation and cancellation are subject to fees.

The correspondences between the information management operations have been revealed, as well as the data groups have been assigned to the operations. Accordingly, the "Charging spot reservation" function is modelled in Figure 3. Indication of data groups is same as in Table 3.

Sequence of operations 3 and 4 can also be the reverse, if the user prefers a spot, where enough time is available to charge his vehicle full. Then the application only offers charging spots meeting this condition. Route planning function $F_{3,1}$ is strongly connected with these operations, as available spots and the current vehicle charging state determine the potential routes.

Maximum duration of reservation (time period while the completely empty battery is to be charged to maximum) is calculated according to Equation. Calculation is associated with the devised function $F_{2,3}$, and is partly embedded in the process of reservation.

$$
t=\frac{Q_{b} \cdot\left(100-S O C_{b}\right)}{P_{c} \cdot \eta},
$$

where state of charge is null, if calculating the maximum duration of charging.

Reservation data and fee are automatically transmitted to a unified, central measurement and account system related to electromobility. Charger operators and electricity providers are connected to this platform. This makes possible providing only a single invoice for customers (EV users). Establishing of a central organization (e.g. clearing house) is a rather challenging requirement as legal, business and technical issues may hinder the implementation. The reliability of data should be guaranteed by all organizations participating in the integrated information management.

After arriving at the charger and connecting the plug, the charger identifies the vehicle and charging process can be started with the help of the application too. Vehicles are 


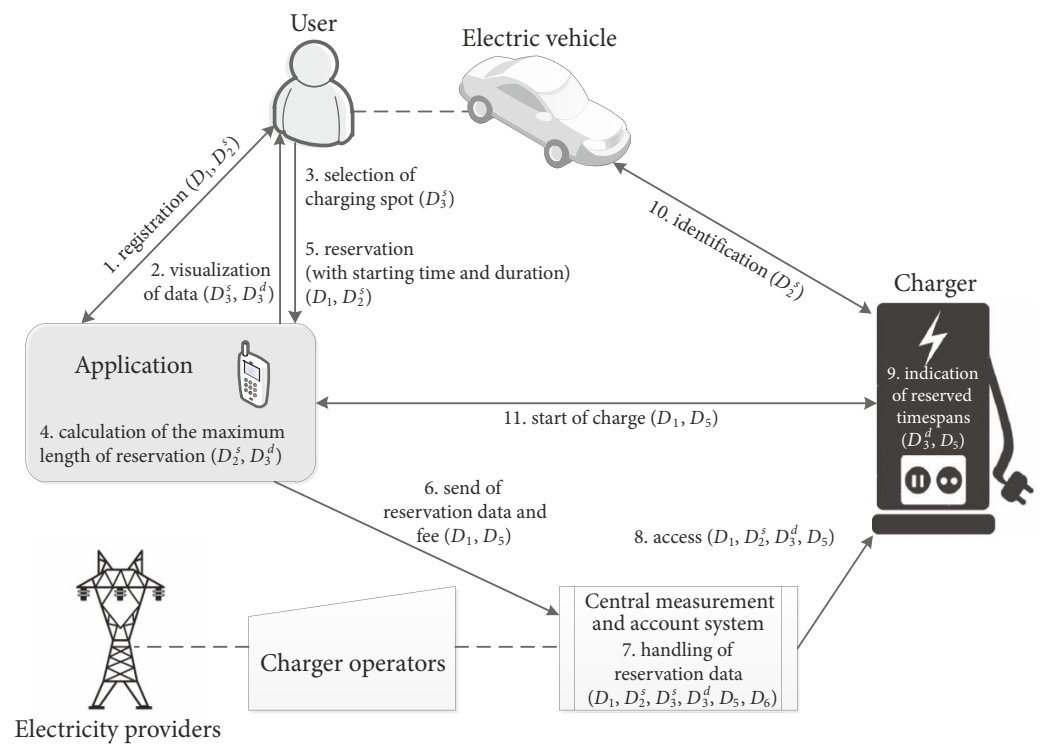

Figure 3. Model of "Charging spot reservation" function

assigned to user's profiles, so the identification of users is also solved in this manner. Communication between the vehicle and the charger is also supervising the charging process. When the battery is fully charged (or the reserved timespan expires) the charging process stops and the cable of the charger becomes removable from the vehicle. Thus, the next driver can immediately use it at the charging stations with more parking lots (it is not necessary to wait for the driver of the previous vehicle to arrive and remove the cable from the car).

Provision of travel information and improvement of predictability are especially important for EV drivers. Impacts of technological drawbacks (e.g. relatively short driving range, long charging times) can effectively be reduced by the results elaborated in our paper. However, it is clearly seen that relevance of driving range issue is decreasing day by day as consequence of emerging battery technologies (Linse, Kuhn 2015).

Similar models have been elaborated for each function to reveal the "inner" correspondences of operations and data groups.

\section{Conclusions}

Advanced information services play a key role in promoting the acceptance of electromobility. EV drivers plan their journey in a more conscious manner, therefore travel information (based on real-time data) are also more valuable for them.

The main contribution of this paper is the concept of an integrated information application aiding electromobility, which has been created by the synthesis of function models. Not only the exemplary functions but the elaborated novel functions were also incorporated into the functional model. The main data groups required for the operation have been identified and classified, also revealing the correspondences between such data groups and the functions. The function model for "Charging spot reservation" has been presented in more detail, to facilitate both journey planning and higher capacity utilization of charging spots. The framework of the information application has also been elaborated including the system architecture.

The integrated application is a rather effective tool to support operation of EVs.

We merged the advantages of current applications and the innovative functions. The level of integration of the "background" system significantly affects the opportunities for functional integration, especially in the cases of functions related to smart metering or grid. The presented concept cannot be realized by solely developing an isolated mobile app. The solution should be supported by systems and software designed specifically for EVs and for charging station operators. This support is especially required for the dynamic functions (e.g. collection of real time data about the state of the vehicle or the charging process). Among current applications, there are already some exemplary solutions; however, the level and dimension of integration are rather limited in most of the cases (e.g. apps are integrated with the chargers of only a few operators). In order to effectively satisfy the demands, providing high quality support for the users, it is essential to ensure a higher level of integration and to incorporate the independent charging possibilities into the concept. This requires close cooperation among organizations of the electromobility market.

By implementation of the information service designed according to the elaborated concept, the following advantages may be obtained:

- rational user decisions;

- increased efficiency of energy management:

- by driving style (eco-driving);

- by navigation (longer range); 
- predictable/calculable journey time - increasing reliability;

- increasing satisfaction/better perceived travel quality. Our future research focuses on:

- analysis of the demands/expectations of travellers towards information management processes and the integrated application (based on a questionnaire survey); incorporating the results of the analysis into the concept;

- elaboration of adaptive, self-learning functions; improvement of the existing functions in this direction.

\section{Acknowledgements}

The research reported in this paper was supported by the Higher Education Excellence Program of the Ministry of Human Capacities in the frame of Artificial Intelligence research area of Budapest University of Technology and Economics (BME FIKP-MI/FM).

\section{References}

Cserháti, B.; Csiszár, C. 2016. Conception of a personalized parking assistant application, Periodica Polytechnica Civil Engineering 60(2): 181-188. https://doi.org/10.3311/PPci.7679

Daina, N.; Sivakumar, A.; Polak, J. W. 2017. Electric vehicle charging choices: Modelling and implications for smart charging services, Transportation Research Part C: Emerging Technologies 81: 36-56. https://doi.org/10.1016/j.trc.2017.05.006

Feijóo, C.; Gómez-Barroso, J. L.; Ramos, S. 2016. Techno-economic implications of the mass-market uptake of mobile data services: requirements for next generation mobile networks, Telematics and Informatics 33(2): 600-612. https://doi.org/10.1016/j.tele.2015.10.001

Földes, D.; Csiszár, C. 2015. Route plan evaluation method for personalised passenger information service, Transport 30(3): 273-285. https://doi.org/10.3846/16484142.2015.1086889

Gonzalez, R.; Gasco, J.; Llopis, J. 2016. Information systems contracts and relationships: A Spanish perspective, Journal of Business Research 69(5): 1696-1700.

https://doi.org/10.1016/j.jbusres.2015.10.040

Huang, M.; Zhou, X.; Li, Q. 2016. Re-visiting axioms of information systems, Information and Computation 247: 130-140. https://doi.org/10.1016/j.ic.2015.12.003

Hübner, Y.; Blythe, P. T.; Hill, G. A.; Neaimeh, M.; Higgins, C. 2012. ITS for electric vehicles - an electromobility roadmap, in IET and ITS Conference on Road Transport Information and Control (RTIC 2012), 25-26 September 2012, London, UK, 1-5. https://doi.org/10.1049/cp.2012.1557

Hung, S.-H.; Shih, C.-S.; Shieh, J.-P.; Lee, C.-P.; Huang, Y.-H. 2012. Executing mobile applications on the cloud: framework and issues, Computers \& Mathematics with Applications 63(2): 573-587. https://doi.org/10.1016/j.camwa.2011.10.044

Karádi, D.; Csiszár, C.; Nagy, E. 2015. Integrated information application on mobile devices for air passengers, in 2015 International Conference on Models and Technologies for Intelligent Transportation Systems (MT-ITS), 3-5 June 2015, Budapest, Hungary, 304-311.

https://doi.org/10.1109/MTITS.2015.7223272
Khoo, H. L.; Ong, G. P. 2011. Analysis of awareness and use of traffic information system with revealed preference data: case study of Klang Valley, Malaysia, Transportation Research Record: Journal of the Transportation Research Board 2239: 101-111. https://doi.org/10.3141/2239-12

Linse, C.; Kuhn, R. 2015. Design of high-voltage battery packs for electric vehicles, in B. Scrosati, J. Garche, W. Tillmetz (Eds.). Advances in Battery Technologies for Electric Vehicles, 245263. https://doi.org/10.1016/B978-1-78242-377-5.00010-8

Merlino, G.; Arkoulis, S.; Distefano, S.; Papagianni, C.; Puliafito, A.; Papavassiliou, S. 2016. Mobile crowdsensing as a service: a platform for applications on top of sensing clouds, Future Generation Computer Systems 56: 623-639. https://doi.org/10.1016/j.future.2015.09.017

Pribyl, O.; Svitek, M. 2015. System-oriented approach to smart cities, in 2015 IEEE First International Smart Cities Conference (ISC2), 25-28 October 2015, Guadalajara, Mexico, 1-8. https://doi.org/10.1109/ISC2.2015.7428760

Samper-Zapater, J. J.; Llidó Escrivá, D. M.; Soriano García, F. R.; Martínez Durá, J. J. 2015. Semantic web service discovery system for road traffic information services, Expert Systems with Applications 42(8): 3833-3842. https://doi.org/10.1016/j.eswa.2015.01.005

Sankaran, K.; Ananda Akkihebba, L.; Chan, M. C.; Peh, L.-S. 2016. Dynamic framework for building highly-localized mobile web DTN applications, Computer Communications 73: 56-65. https://doi.org/10.1016/j.comcom.2015.08.017

Tavares, A. S.; Gálvez, C.; De Albuquerque, L. W. N.; Almeida, A. L.; Barros, R. Q.; Soares, M.; Villarouco, V. 2015. Information on public transport: a comparison between information systems at bus stops, Procedia Manufacturing 3: 6353-6360. https://doi.org/10.1016/j.promfg.2015.07.958

ThinkMobile. 2011. The Mobile Movement: Understanding Smartphone Users. 39 p. Available from Internet: https://ssl.gstatic. com/think/docs/the-mobile-movement_research-studies.pdf

Walravens, N. 2015. Mobile city applications for Brussels citizens: smart city trends, challenges and a reality check, Telematics and Informatics 32(2): 282-299.

https://doi.org/10.1016/j.tele.2014.09.004

Wydro, K. B. 2010. A measurement of the information value in transport processes, Communications in Computer and Information Science 104: 210-217. https://doi.org/10.1007/978-3-642-16472-9_23

Wydro, K. B. 2011. Basics of transport information management, Archives of Transport System Telematics 4(3): 36-42. 